Results In a total of 24 providers courses during the 2008 and 2012, 529 doctors participated and among them 417 completed the course successfully. 43 faculty members also developed to run the course. Trained $87.5 \%$ doctors are using EMSB skills in burn management. About 38\% doctor felt that the course helped them to improve their confidence. Majority of doctors stated EMSB is essential for the Bangladeshi doctors to learn better management of burn. From qualitative study it was found that the courses maintaining same quality and standard as running anywhere in the world. However, it has recommended to train nurses and more doctors from periphery of the country.

Conclusions EMSB created a large doctors community who are effectively managing burn patients. It also create demand for learning burn management skill. EMSB training is required for medical doctors and nurses at the grass root level which could avert a number of deaths and also reduce the severity of the burn injuries.

\section{A SAFER CANDLE PROJECT SOUTH AFRICA}

PP Mtambeka, D Schulman, N du Toit, H. Rode, AB Van As. Childsafe South Africa, Red Cross War Memorial Children's Hospital

\subsection{6/injuryprev-2016-042156.802}

Background There are two main causes of shack fires in South Africa: Fallen candles and paraffin-related burns. These fires lead to devastating consequences and huge economic losses.

Aim/goal The goal of this project is to facilitate and promote safer use of candles in a glass jar, with the ultimate aim to prevent fires, burn injuries and deaths caused by fallen candles, targeting individuals and families who live in informal homes.

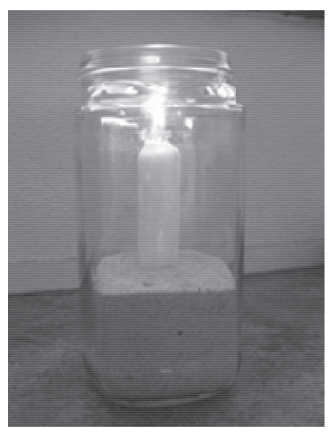

Material and methods Childsafe South Africa personnel conducted a number of trials to test the "Candle in a glass jar" concept. In 2006, the project was piloted in an informal area that exclusively uses candles as source of light. Further demonstration and educational sessions have taken place and over 100,000 jar units have been distributed to various communities to date.

Results The Safer Candle Project has become one of Childsafe's established out-reach programmes over 10 year period.It has been widely accepted and been approved by World Wide Fund for Nature SA (WWF) for Earth Hour and endorsed by various stakeholders and sponsors.

Significance The idea of candle in the glass jar is recommended as its very simple and preventative measure to reduce fires mainly caused by candles tipping. One of its advantages is that it places no financial burden on families, as there are virtually no costs involved.

\section{FIRE SAFETY PRACTICES IN INSTITUTIONAL, RESIDENTIAL AND HOME CARE IN FINLAND}

Markus Grönfors, Tarja Ojala, Nina Martikainen, Satu Pajala, Anne Lounamaa. National Institute for Health and Welfare, Finland

\subsection{6/injuryprev-2016-042156.803}

Background The rescue act 2011 in Finland stresses that the responsibility of fire safety is on building owners and service providers. The regulation is justifiable, because people in vulnerable positions, for example elderly and disabled, have an increased risk being fire victims.

The aim of this study was to investigate the implementation of rescue service act among service providers in residential, institutional and home care facilities and to monitor changes from 2013 to 2015.

Methods Online surveys on fire hazard assessment and risk management practices were done in 2013 and 2015. Respondents were managers of residential, institutional and home care facilities for the vulnerable people.

Information of the facilities was obtained from the nationwide Register of Institutions in Social Welfare and Health Care. The study sample was systematically selected (every other) and it consisted 1605 organisations.

Results In 2013 93\% of institutional and 95\% residential units had written guidelines to ensure fire safety. In 2015 the proportion has decreased to 84 in institutional and $88 \%$ in residential units. At home care written guidelines had less than $50 \%$. The accident prevention guidelines had increased in institutional units from $66 \%$ to $74 \%$ and in residential units from $66 \%$ to $77 \%$. At home care the guidelines had $50 \%$. Safety guidelines in general e.g. crime prevention has also decreased and was now less than 50\%, at home care only $22 \%$. Patient and residential safety guidelines were increased only at home care from $55 \%$ to $60 \%$.

Conclusions The organisations have increased their preparedness for fire risk with sprinklers. But at the same time they made less written guidelines to prevent to fire. Fire risk assessment and management practices have improved only in home care. In IR-units the situation seems to be weaker than in 2013. The situation is not acceptable and the reasons should be diagnosed.

\section{Preparedness and Resilience}

\section{Post Tue 2.21}

\section{LEVEL OF PREPAREDNESS FOR PREVENTION AGAINST TERRORISM IN LIBRARIES: IMPLICATIONS FOR LIBRARIANS IN NIGERIA}

Roseline Echezona, Bredan Asogwa, Emmanuel Chigbue. University of Nigeria, NSUKKA

\subsection{6/injuryprev-2016-042156.804}

Introduction Terrorism is becoming a common occurrence in the world today. They came like robbers. In Africa and other developing countries of the world terrorism is prevalent. Most reports on terrorist attacks revealed that they strike when no one expected.

In Nigeria, terrorist activities which started in 2009 is still on. Boko Haram Islamic militants have unleashed devastating havoc on Nigerians through bombing of worshipping centres that if 
adequate preparations are not established in universities, the libraries may face imminent attacks and destruction by the Islamic terrorist group.

The main objective of this paper is to examine the level of preparedness of libraries in Nigerian against terrorist attack. Specifically the study will assess the level of awareness of librarians about terrorism; examine the security policies available against terrorism in the libraries.etc

The population of the study will be all academic librarians from which management staff in the library and chief security officers in Nigerian universities will be sampled. Questionnaire and interview will be used for data. The purpose for sampling this category of librarians was because they are always involved in the policy making and policy implementations in their libraries.

Findings Libraries have policies on security, but such policies have neither been expanded nor updated to cover aspects of terrorism and man-made disasters. In view of these possible findings, academic libraries in Nigeria seem not to be adequately prepared to forestall imminent attack by terrorists on libraries in Nigerian universities. For that the implications remains that academic libraries may lose substantial volume of irreparable and irreplaceable workforce, facilities, resources and others.

The Paper recommends that more awareness about the dangers of terrorism and their mode of operation should be intensified not in the library but also in the university community. This should be done using jingles, notice boards, bill boards and other information provision media. Electronic detective machines for finding dangerous weapons should be installed in the libraries by the federal government. Library policies on security should be expanded and updated to include safety of human and library resources and be seriously implemented.

\section{SIGNIFICANCE OF GRIEF CARE EDUCATION FOR YOUTH: AN EVALUATION OF TRAUMA-PREVENTION CLASS OF P. A.R.T.Y PROGRAM IN JAPAN}

${ }^{1}$ Hideko Kojima, ${ }^{2}$ Yoshikazu Kojima. ${ }^{1}$ Kitasato University, Japan; ${ }^{2}$ University of Tokai, Japan

\subsection{6/injuryprev-2016-042156.805}

Background Trauma-Prevention class for adolescents, as part of P. A.R.T.Y Program (Prevention of Alcohol and Risk-Related Trauma in Youth), was held from 2006 and 2011. From the participant evaluation it became clear that many participants had stronger interest toward psychological trauma than in physical trauma (Kojima 2014). Thus from 2011 a program of "Loss and Grief" had been added. The purpose of the present study is to ascertain the significance of this new program.

Method A free-response evaluation was obtained from the participants of the trauma-prevention class (P.A.R.T.Y Program) for adolescents from 2006 to 2011. The educational effectiveness of the program "Loss and Grief" was assessed through a qualitative analysis of relevant part of the evaluation. Ethical approval was gained from the Ethics Committee at Kitasato University.

Results Response from 74 out of 105 participants were obtained, and the qualitative analysis of the data yielded 74 raw data, 13 codes, 6 sub-categories and 3 categories. Participants construed "Loss and Grief" as an opportunity to learn that experience of loss varies among individuals and that it is important to understand what life and loss mean for oneself. They also learned the importance of thinking for themselves how to respond to loss, but also of mutual support and sympathy.

Conclusion In Japanese high school education there is no class related loss and grief care, thus adolescents do not have the opportunity to learn about the meaning of loss. By including a study of psychological traumas in the prevention of trauma class (P.A.R.T.Y Program), students can learn that the feeling of loss following physical traumas in oneself or dear ones is a natural phenomenon and can also become interested in learning about the emotional significance of loss and its treatment. Henceforth we plan to include "Experience of Loss and Grief Process" into the program and further refine the prevention of trauma class ( $P$. A.R.T.Y Program) by continuously incorporating feedback from participants.

\section{THE DISASTER TRAUMATIC PREVENTION CLASSROOM INTRODUCED ACTIVE LEARNING}

${ }^{1}$ Yoshikazu Kojima, ${ }^{2}$ Hideko Kojima. 'Startup Project, Faculty of Nursing, Tokyo University of Information Sciences; ${ }^{2}$ Kitasato University, Japan

\subsection{6/injuryprev-2016-042156.806}

Background Japan is located where four tectonic plates meet: the Pacific, North American, Eurasian, and Philippine plates. One hundred million people live in this region, which contains many rivers and mountain ranges, including volcanoes. The government has maintained public facilities at an advanced level in order to cope with natural disasters. However, the government has not yet established a practice whereby potential victims could learn to survive.

Objective The development of the learning program to win the Trauma/Injury prevention capacity at the time of Disaster occurred for High school students was held a Learning Course incorporating the Active Learning strategies.

Results We held the course eleven times between September 2011 and August 2015. A total of 208 students participated. Program content and Learning forms were Lecture which used for Interactive classroom technology, as below Explain of P.A.R.T.Y Program in Isehara and Learning about disaster prevention, Features of Disaster, Coping with Grief and Loss, High Energy Trauma Management, Life of Higher brain dysfunction and Activity of DMAT(Disaster Medical Assistance Team). Simulations which use Simulation Lab or Centre were Basic fire-fighting Training, Smoke escape training and Escape from the darkroom. Visiting style of the tour of Emergency Department are Helicopter Emergency Medical Service and Emergency Department. Practices of small group training were Art of self-defense, First aid training and How to Cover Up Scars.

Conclusions Learning how to prevent trauma during disasters is an important life skills. However, many young people are not interested in it, because it is not a fun experience. Active learning methods are effective; however, participants with low motivation are not welcome to take part in the course.

We make the course map for discuss the disaster-related issues mentioned with the participants.

Disaster prevention, 2. P.A.R.T.Y Program, 3. Youth, 4. Active learning 